\title{
Male Breast Cancer with Radiological and Histopathological Findings
}

\author{
(Dennet Sahin, ${ }^{1}$ C Burcin Agridag Ucpinar, ${ }^{1}$ () Deniz Turkyilmaz Mut, ${ }^{1}$ () Onur Yilmaz, ${ }^{1}$ () Ramazan Ucak, ${ }^{2}$ \\ (D) Cemal Kaya, ${ }^{3}$ (i) Canan Tanik ${ }^{2}$
}

'Department of Radiology, Istanbul Sisli Hamidiye Etfal Training and Research Hospital, Istanbul, Turkey ${ }^{2}$ Department of Pathology, Istanbul Sisli Hamidiye Etfal Training and Research Hospital, Istanbul, Turkey

${ }^{3}$ Department of General Surgery, Istanbul Sisli Hamidiye Etfal Training and Research Hospital, Istanbul, Turkey

\begin{abstract}
Objectives: We aimed to remind and emphasize the importance of male breast cancer with radiological and histopathological results of the patients diagnosed in our institution.

Methods: Men who had proven breast cancer by histopathological analysis between February 2010-April 2018 were reviewed retrospectively. The mammographic, ultrasonographic, magnetic resonance and positron-emission-tomography imaging features and histopathological results of the masses were noted.

Results: Twenty-five men were included in this study. Mean age of the patients was 62.9 (min:42; max: 82 ) with a mean size of lesions was $26.4 \mathrm{~mm}$ ( $\min : 10 \mathrm{~mm}$; max: $70 \mathrm{~mm}$ ). All the lesions were presented as a palpable mass. According to imaging features of the five patients who had mammography, all the four patients were presented as a mass but one patient as asymmetrical density. According to imaging features of the 20 patients who had an ultrasound, $16(80 \%)$ lesions were presented as hypoechoic solid masses with irregular margins, while four (20\%) were presented as complex-cystic masses with irregular margins. All the patients were diagnosed as invasive ductal cancer with luminal subtype by histopathological analysis.

Conclusion: Even at young ages, the palpable lesion may be the only symptom of male breast cancer. Male breast cancer is generally presented as retroareolar mass and detected in advanced stages, probably due to low awareness and lack of screening programme. Invasive ductal cancer is the most common type of male breast cancer with the luminal subtype.

Keywords: Awareness; histopathological analysis; imaging features; male breast cancer; mammography; ultrasound.

Please cite this article as "Sahin C, Agridag B, Turkyilmaz Mut D, Yilmaz O, Ucak R, Kaya C, et al. Male Breast Cancer with Radiological and Histopathological Findings. Med Bull Sisli Etfal Hosp 2020;54(3):375-379".
\end{abstract}

$M^{2}$ ale breast cancer (MBC) accounts for approximately $1 \%$ of all breast cancers and it is very rare compared to the female population. ${ }^{[1,2]} \mathrm{MBC}$ is generally seen in later decades of life (in 60-70 years of age) compared to female's breast cancer. ${ }^{[1,2]}$ However, the importance of MBC should not be ignored due to its poorer prognosis since being diagnosed in later stages. Some of the risk factors for the development of breast cancer in the male population are age, having a history of breast cancer in first-degree male or female relatives, hyperestrogenism, a history of radiation to the mediastinum, a history of exogenous estrogen usage and having genetic predisposition (as BRCA1 or BRCA2 mutations, Kleinfelter syndrome) ${ }^{[3-5]}$ Invasive ductal carcinoma (IDC) is the most common subtype. ${ }^{[3-5]} \mathrm{MBC}$ generally presents with the unilateral, fixated, painless subareolar mass lesion. ${ }^{[5-7]}$ In MMG, as most of MBC (s) may be presented as a spiculated mass with irregular or indistinct borders, also in $15 \%$ of the cases, it may be presented as dens nodular mass lesion with distinct borders ${ }^{[6]}$ In this study, we aimed to remind and emphasize the importance of $M B C$ and to

Address for correspondence: Cennet Sahin, MD. Istanbul Sisli Hamidiye Etfal Egitim ve Arastirma Hastanesi, Radyoloji Klinigi, Istanbul, Turkey Phone: +90 5057485741 E-mail: cennetsahin2@hotmail.com

Submitted Date: December 31, 2019 Accepted Date: April 21, 2020 Available Online Date: August 22, 2020

${ }^{\circ}$ Copyright 2020 by The Medical Bulletin of Sisli Etfal Hospital - Available online at www.sislietfaltip.org

OPEN ACCESS This is an open access article under the CC BY-NC license (http://creativecommons.org/licenses/by-nc/4.0/) 
demonstrate radiologic and histopathological findings of $M B C$ diagnosed in our institution.

\section{Methods}

The institutional review board of our hospital approved this study (Number: 2353, Date: 16.04.2019). Patient informed consent was obtained before any invasive procedures. The male patients who had a diagnosis of breast cancer proven by histopathological analysis (with either mastectomy, excisional biopsy or percutaneous core-needle biopsy specimens) between February 2010 and April 2018 were reviewed retrospectively. Clinical, imaging and histopathological records were reviewed retrospectively from HIMS (hospital information management system) and PACS (Picture archiving and communication system) database at our institution. All the archived images, including mammograms (MMG) (Mammomat, Siemens, Erlangen; Germany) on both craniocaudal (CC) and medio-lateraloblique (MLO) positions, ultrasound (US) (with a 12-4-MHz linear array transducer; Mindray, China), Magnetic Resonance Images (MRI) and Positron Emission TomographyComputed Tomography (PET-CT) images, were evaluated by two radiologists with 3-8 years of experience in breast radiology. The morphological feature, size, localization of each lesion and presence of axillary lymph node involvements were evaluated and radiologic features were documented according to the BI-RADS (Breast Imaging-Reporting and Data System) lexicons. ${ }^{[6,7]}$ Mammographic findings were reviewed for the location, shape, margin, and density of masses, morphologic characteristics, and distribution of calcifications; and associated findings, such as skin, nipple, or pectoralis muscle involvement. Ultrasonographic parameters were evaluated for type (solid, complex cystic or architectural distortion), shape, margin, echogenicity of lesions. Axillary nodal positivity was proven with either USguided fine-needle aspiration biopsy, axillary nodal dissection or sentinel node biopsy. Histopathology samples were evaluated by two dedicated breast pathologists with 10 and 15 years of experience. The histopathological results of molecular subtype information were documented for each mass additionally.

\section{Statistical Analysis}

For statistical analysis, Statistical Package for the Social Sciences (SPSS) for Windows (Version 21.0, Chicago, SPSS Inc.) program was used. Descriptive statistics were given as number and percentage for categorical variables and as mean, standard deviation, minimum, maximum and median for numerical variables. Ratios in independent groups were tested using Chi-Square Analysis. Statistical significance was defined as a $p$-value of $\leq 0.05$

\section{Results}

A total of 39 male patients who had a diagnosis of breast cancer between February 2010 and April 2018 were reviewed retrospectively. Twenty-five were included in this study while the rest of 14 were excluded from this study due to lack of radiologic and pathologic information. Mean age of the patients were $62.9 \pm 12.2$ ( $\min : 42 ; \max : 82$ ). The mean size of the lesions was $26.4 \pm 14.9 \mathrm{~mm}(\mathrm{~min}: 10 \mathrm{~mm}$; max: $70 \mathrm{~mm}$ ), and $75 \%$ of the lesions were larger than 20 $\mathrm{mm}$. One patient had two multifocal lesions. All the patients had the complaint of a palpable mass in the breast, while $40 \%$ of the patients had bloody nipple discharge. Of all masses, $70 \%$ were in retroareolar location and $30 \%$ were eccentric (Fig. 1). Twenty (80\%) patients had US images with or without MMG, MR or PET-CT images, five (20\%) patients had MMG, three (12\%) patients had MR images, five (20\%) patients had only PET-CT images on PACS database as radiologic work-up. According to imaging features of MMG(s), all the four lesions were presented as a mass lesion with spiculated margins but one presented as asymmetrical density. Only in one (4\%) of the patients, one punctate microcalcification was present in the mass (Fig. 2). Accord-

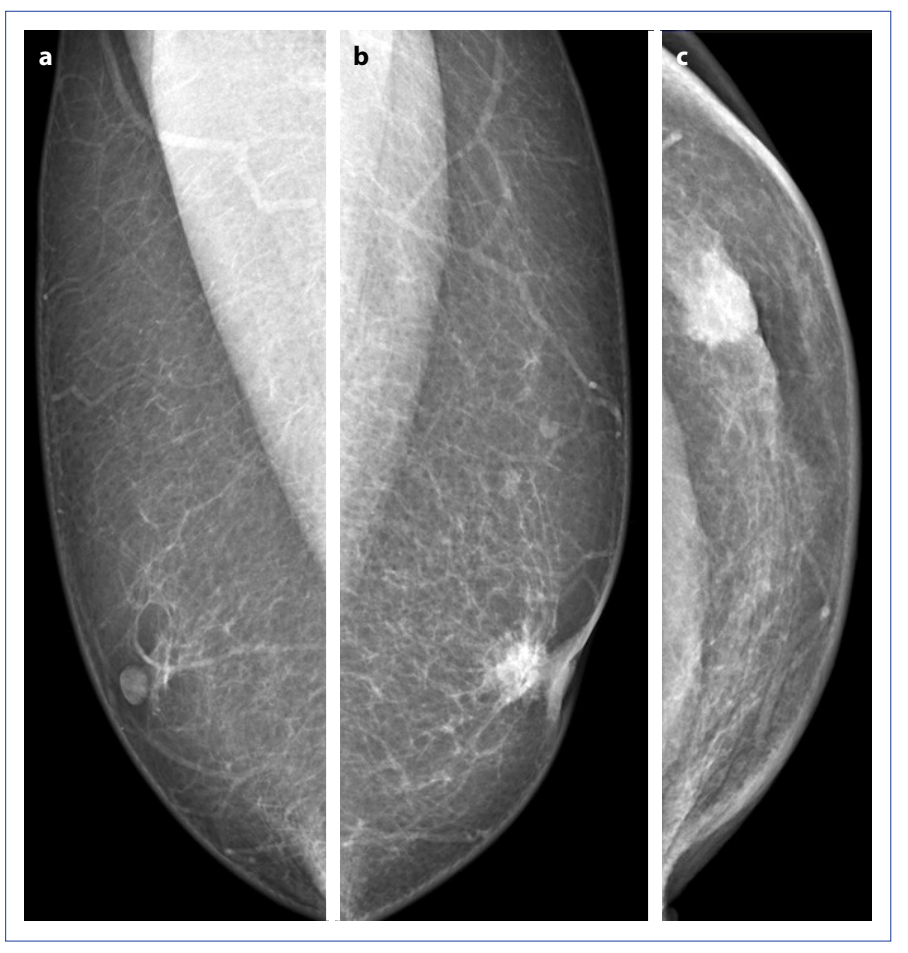

Figure 1. A radiopaque mass with irregular margins was seen on the left MMG image of an 80 years old male $(\mathbf{a}, \mathbf{b})$. The lesion was in retroareolar position, causing nipple retraction. In another patient who was an 80 years old male, a radiopaque mass with irregular and indistinct margins in eccentric localization (not retroareolar) is seen on the left MMG image (c). Both of the patients were diagnosed as invasive ductal carcinoma. 


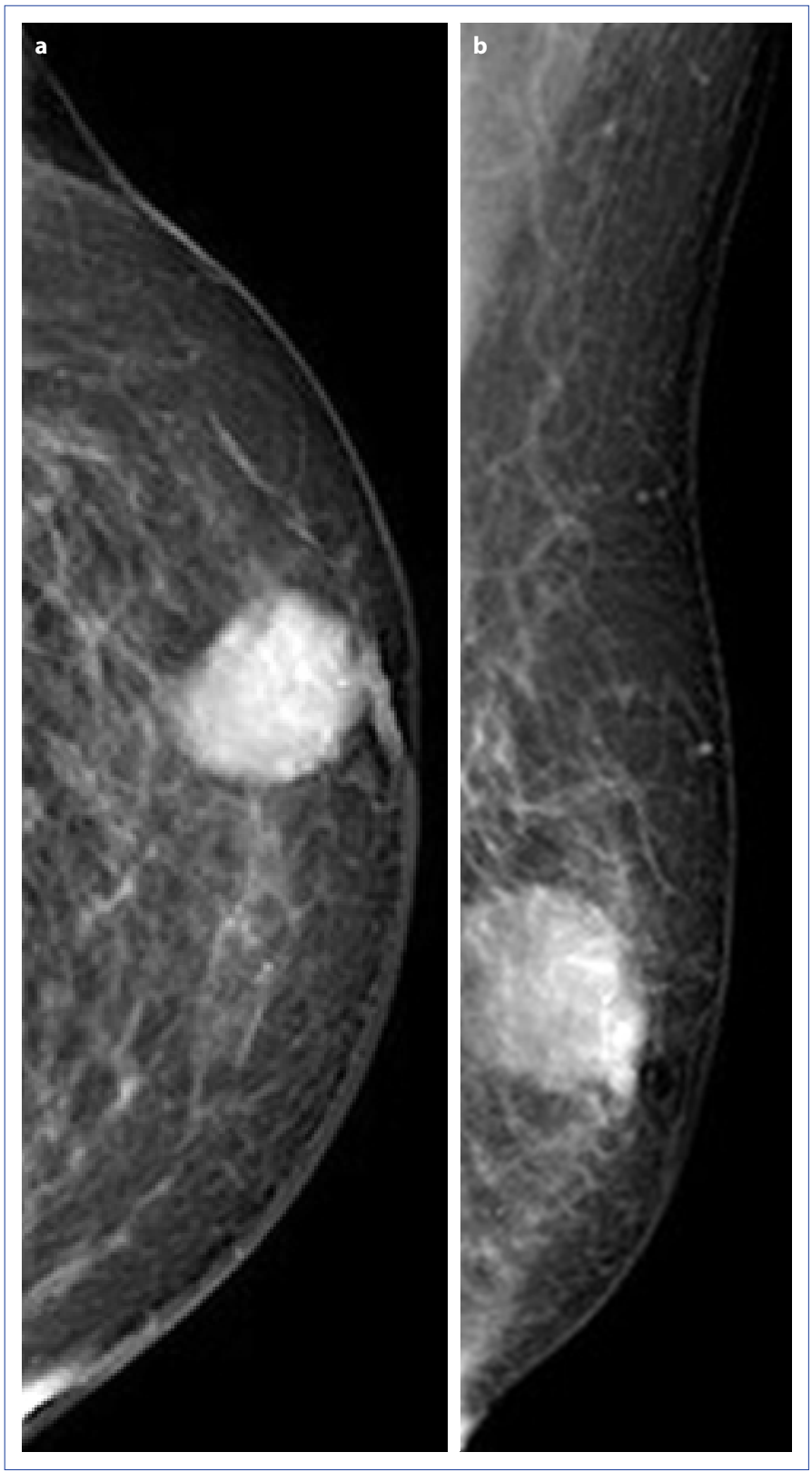

Figure 2. Left mammography images of a 70 years old male who was diagnosed as invasive ductal carcinoma were shown. $\mathrm{A} 3 \mathrm{~cm}$ radiopaque mass lesion with lobulated contours and punctate microcalcifications inside was seen in retroareolar localization on CC and MLO projections of left MMG $(\mathbf{a}, \mathbf{b})$.

ing to the US imaging features of 20 patients, $16(80 \%)$ of the lesions were presented as hypoechoic solid masses with irregular margins while four (25\%) lesions were presented as complex cystic masses with irregular margins (Fig. 3). The lesions were FDG avid in all the PET-CT images. There were two patients who had received radiotherapy to mediastinum in background history. One of them had received radiotherapy due to lung cancer, and the other patient had due to contralateral breast cancer (Fig 4). Thir-

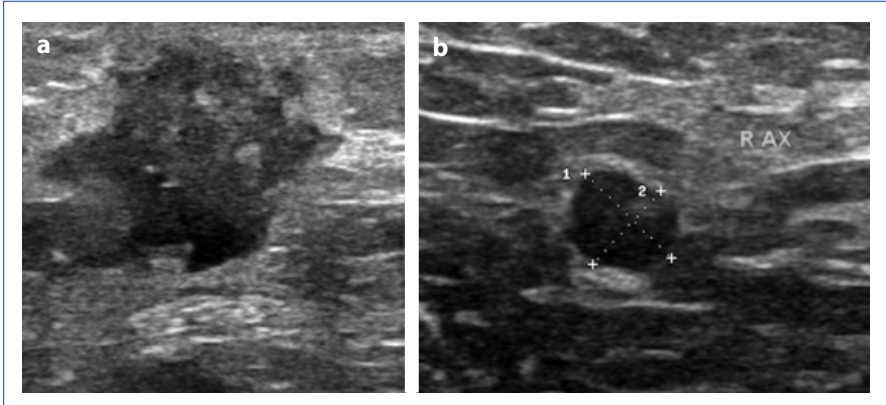

Figure 3. A $25 \mathrm{~mm}$ hypoechoic solid mass with irregular margins was seen on the US image of a 73 years old male who was diagnosed with invasive ductal carcinoma (a). Hypoechoic, round formed that was $9 \times 6 \mathrm{~mm}$ in size metastatic lymph node was also seen in axillary region ipsilaterally (b).

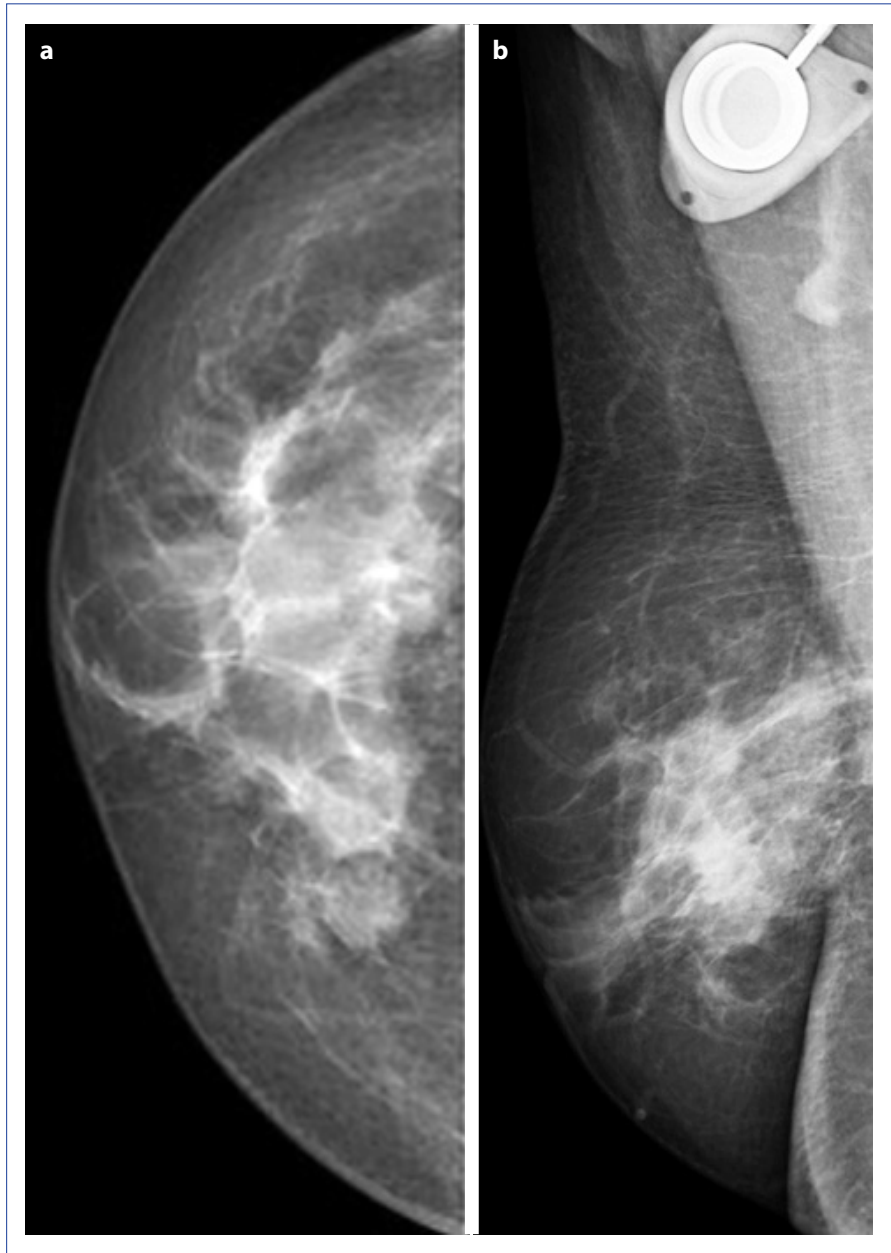

Figure 4. A non-mass opacity with ill-defined contours was seen located in the right breast in a 62 years old male patient who had contralateral breast cancer in background history. Adjacent to the lesion medially, a round formed lymphadenopathy was seen on CC image (a). The radiopaque artifact due to the chemotherapy port was seen on MLO image (b). Histopathological diagnosis revealed invasive ductal carcinoma in this patient, similar to the previous breast cancer history. 
teen of the patients had a histopathological diagnosis by the US-guided core-needle biopsy, 12 were diagnosed by operation specimen. According to histopathological evaluation, all the 25 patients were diagnosed as IDC (84\% nonspecific, $16 \%$ micropapillary variant) (Fig. 5). Molecular subtypes were evaluated for all the lesions. Of these, 15 (60\%) lesions were diagnosed as Luminal-A, seven (28\%) lesions were diagnosed as Luminal-B, and three $(12 \%)$ lesions were diagnosed as Her2 + Luminal-B in subtypes. None of the lesions was evaluated as triple-negative. There was axillary lymph node metastasis in $17(68 \%)$ and skin involvement in three (12\%) of the patients (Fig. 6) at the time of diagnosis.

\section{Discussion}

The incidence of breast cancer in the male population has been reported by approximately $1 \%$ in the literature. ${ }^{[1,2]}$ There are many review articles in the literature about breast cancer in the male population. However, there are very few reports about the case series of male breast cancer proven by histopathological analysis. ${ }^{[8-13]}$ To our knowledge, our study is one of the very few studies describing

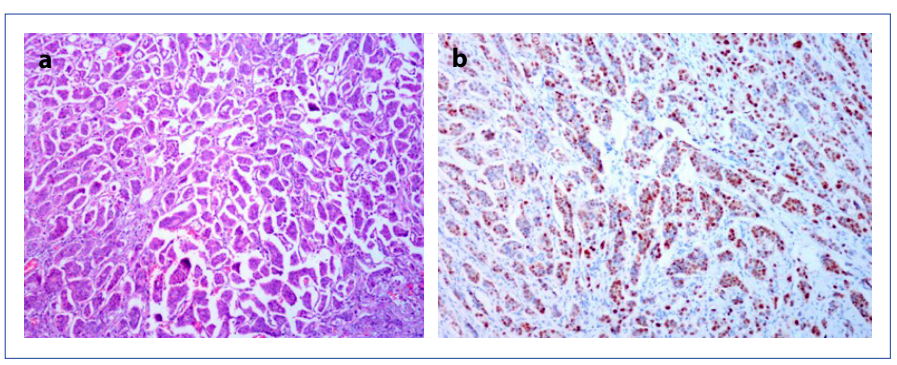

Figure 5. Histopathological images showed an invasive micropapillary pattern. The tumor composed of clusters floating in empty spaces (hematoxylin-eosin staining, at magnification x100) (a). Intense nuclear immunoreactivity with Cyclin D1 in the micropapillary carcinoma area was seen in Figure b IHC, X100 (hematoxylin-eosin staining, at magnification $\times 100$ ).

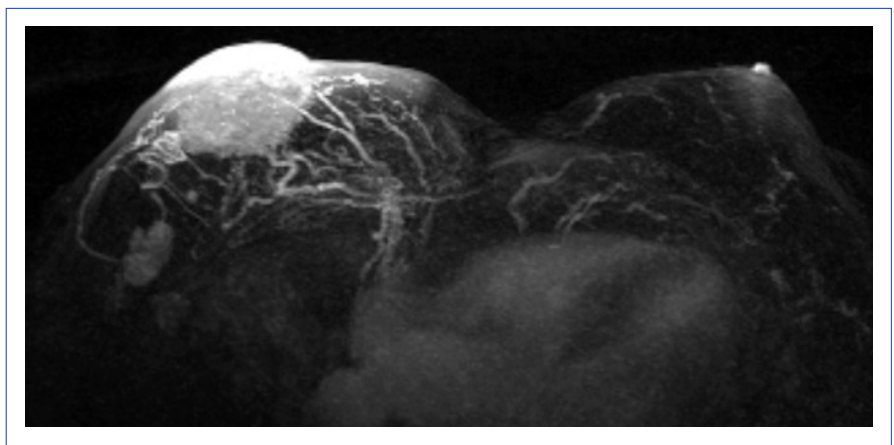

Figure 6. A 69 years old male who was diagnosed with invasive ductal cancer, including a micropapillary variant in the right breast. The mass was exophytic in retroareolar localization. The skin involvement and axillary metastasis were demonstrated clearly in this contrast-enhanced MRI. the radiologic and histopathological features of breast cancer in men who were diagnosed in an institution different from the reviews in the literature.

In the male population, breast cancer is most commonly seen between the ages of 60 and 70 years that are about 5-10 years above the average age of women's breast cancer. ${ }^{[3-5]}$ Although the mean age of the patients was 62,9 years in this study, two patients were younger than 45 years old. Thus, the diagnosis of MBC in even the young male population should be kept in mind. MBC is generally detected in advanced stages because of the delay in diagnosis. ${ }^{[14]}$ Consistent with this knowledge, $75 \%$ of the lesions were larger than $20 \mathrm{~mm}$ in this study. Also, $68 \%$ of the patients had axillary metastasis. Although cancer diagnosis should be easier because of the easier detection of a mass in such a small size of breast in men, most of the patients in this study were not diagnosed in early stages. We assume that this may be a result of a lack of awareness of breast cancer in the male population.

There is no standardized screening programme for MBC. Although having the breast cancer diagnosis, post-treatment radiologic follow-up in men is also poor. Although MMG should be the first imaging modality in men with a palpated mass lesion in breast, due to easy accessibility and lower prices of sonographic imaging, the US may be chosen as the first-line imaging modality most of the times and patients may undergo biopsy without having MMG examination. ${ }^{[11-13]}$ In our study, $80 \%$ of all of the patients had undergone US examination while only $20 \%$ were evaluated with MMG. In MMG, microcalcifications (that are in less number, more coarse and non-linear form compared to female's) may accompany in $30 \%$ cases. In this study, cancer was presented as mass opacity with microcalcifications, just in $4 \%$ of the cases who had MMG. ${ }^{[11-13]}$ Because of the lack of standardization in male breast cancer imaging, magnetic resonance imaging (MRI) is not used as often as female breast cancer. ${ }^{[15]}$ Only three of the cases in our study were examined using MRI which helped detect skin involvement and axillary metastasis. We think that MRI may be performed in male cancer if skin involvement, axillary metastasis or multifocality-multicentricity is suspected.

The majority of breast cancers in the male population are diagnosed as invasive ductal cancers. Since male breast tissue is composed of undeveloped ducts, the possibility of invasive lobular cancer is very rare and since cancer is not detected in the early stages, the possibility of in situ ductal cancer is very rare, too. ${ }^{[3,4]}$ In this study, there was no case that was diagnosed as neither in-situ cancer nor invasive lobular cancer.

All the biopsy samples were evaluated by two experienced 
pathologists. They determined the final diagnosis of each case with consensus. As the molecular subtypes were examined in this study, 15 (60\%) of the cancers were in luminal $A$, seven $(28 \%)$ were in luminal $B$, three $(12 \%)$ were in HER2 positive subtypes. None of the patients had a triplenegative subtype. We had four cases that were diagnosed as a micropapillary variant, which is a really rare subtype of $M B C$ that there are only a few cases established in the literature. ${ }^{[16]}$ Histopathological diagnosis, including molecular subtype of MBC, can be easily detected by ultrasonography-guided percutaneous core-needle biopsy.

There are some limitations of this study. One of them is being a retrospective study with a limited number of cases. All the images were reviewed retrospectively; thus, only a few patients had MMG imaging. The last, we were not aware of the family history or genetic disposition of the patients for breast cancer.

\section{Conclusion}

In conclusion, even in young men, the palpated lesion in male breast can be the only symptom of cancer. MBC generally is presented as a retroareolar mass and generally detected in advanced stage probably due to lack of awareness of the male population and lack of screening programme. IDC is the most common type of MBC and the luminal type is the most common seen molecular subtype.

\section{Disclosures}

Ethics Committee Approval: The Ethics Committee of Sisli Hamidiye Etfal Training and Research Hospital provided the ethics committee approval for this study (16.04.2019-2353).

Peer-review: Externally peer-reviewed.

Conflict of Interest: None declared.

Authorship Contributions: Concept - C.S., B. A. U., D. T. M., O. Y.; Design - C.S., B. A. U., O.Y.; Supervision - C.S., B.A.U.; Data collection \&/or processing - C.S., B.A.U., D.T.M., O.Y., R.U., C.K., C.T.; Analysis and/or interpretation - C.S., B. A.U., D.T.M., O.Y., R.U., C.K., C.T.; Literature search - C.S., B.A.U.; Writing - C.S., B. A. U.; Critical review - C.S., B.A.U.

\section{References}

1. Giordano SH, Cohen DS, Buzdar AU, Perkins G, Hortobagyi GN. Breast carcinoma in men: a population-based study. Cancer 2004;101:51-7. [CrossRef]

2. Anderson WF, Jatoi I, Tse J, Rosenberg PS. Male breast cancer: a population-based comparison with female breast cancer. J Clin Oncol 2010;28:232-9. [CrossRef]

3. Nguyen C, Kettler MD, Swirsky ME, Miller VI, Scott C, Krause R, et al. Male breast disease: pictorial review with radiologic-pathologic correlation. Radiographics 2013;33:763-79. [CrossRef]

4. Sanguinetti A, Polistena A, Lucchini R, Monacelli M, Galasse S, Avenia $S$, et al. Male breast cancer, clinical presentation, diagnosis and treatment: Twenty years of experience in our Breast Unit. Int J Surg Case Rep 2016;20S:8-11. [CrossRef]

5. Yildirim E, Berberoğlu U. Male breast cancer: a 22-year experience. Eur J Surg Oncol 1998;24:548-52. [CrossRef]

6. American College of Radiology (ACR). ACR BI-RADS, mammography. In: ACR breast imaging re- porting and data system: breast imaging atlas. 4th ed. Reston, VA: American College of Radiology; 2003.

7. American College of Radiology (ACR). ACR BI- RADS, ultrasound. In: ACR breast imaging reporting and data system: breast imaging atlas. 4th ed. Reston, VA: American College of Radiology; 2003.

8. Yuan WH, Li AF, Chou YH, Hsu HC, Chen YY. Clinical and ultrasonographic features of male breast tumors: A retrospective analysis. PLoS One 2018;13:e0194651. [CrossRef]

9. Bagnera S, Campanino P, Barisone F, Mariscotti G, Gandini G. Imaging, histology and hormonal features of five cases of male breast cancer observed in a single year: comparison with the literature. Radiol Med 2008;113:1096-109. [CrossRef]

10. Mathew J, Perkins GH, Stephens T, Middleton LP, Yang WT. Primary breast cancer in men: clinical, imaging, and pathologic findings in 57 patients. AJR Am J Roentgenol 2008;191:1631-9. [CrossRef]

11. Yang WT, Whitman GJ, Yuen EH, Tse GM, Stelling CB. Sonographic features of primary breast cancer in men. AJR Am J Roentgenol 2001;176:413-6. [CrossRef]

12. Dershaw DD, Borgen PI, Deutch BM, Liberman L. Mammographic findings in men with breast cancer. AJR Am J Roentgenol 1993;160:267-70. [CrossRef]

13. Partik B, Mallek R, Rudas M, Pokieser P, Wunderbaldinger $P$, Helbich TH. Malignant and benign diseases of the breast in 41 male patients: mammography, sonography and pathohistological correlations. Rofo 2001;173:1012-8. [CrossRef]

14. Fentiman IS. Surgical options for male breast cancer. Breast Cancer Res Treat 2018;172:539-44. [CrossRef]

15. Shaw A, Smith B, Howlett D. Male breast carcinoma and the use of MRI. Radiol Case Rep 2015;6:455. [CrossRef]

16. Oguz A, Aykas F, Kaya FC, Unal D, Tasdemir A. Pure micropapillary carcinoma of breast: A quite rare subtype. Indian J Cancer 2014;51:576. [CrossRef] 